\title{
Prototipe Alat Pengusir Burung pada Gedung Berbasis Internet of Things menggunakan Sensor RCWL
}

\author{
Ali Khumaidi \\ Program Studi Teknik Informatika Universitas Krisnadwipayana, Jl. Jatiwaringin, Pondok Gede, 17411, Jakarta \\ alikhumaidi@unkris.ac.id
}

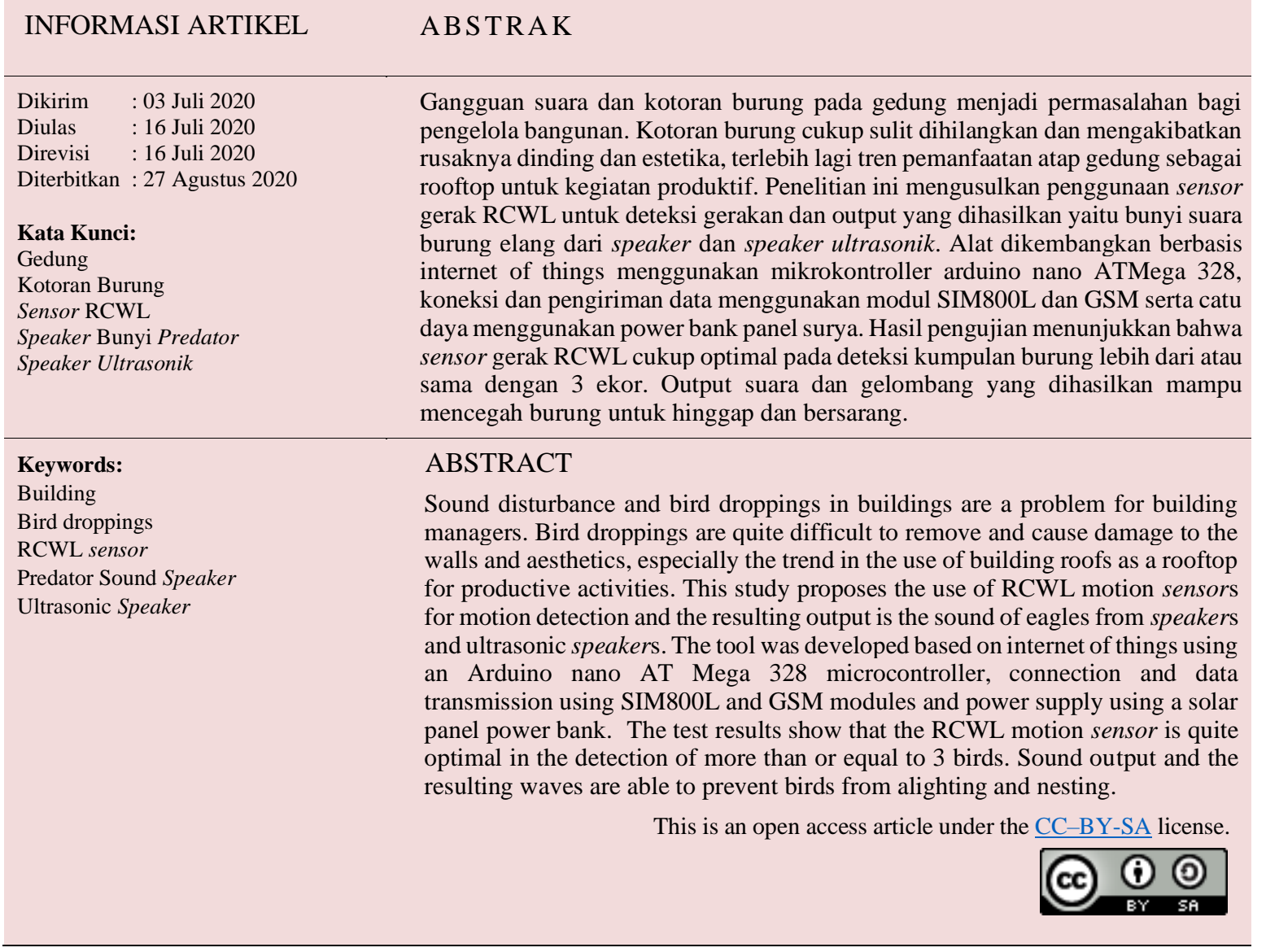

\section{Pendahuluan}

Burung merupakan jenis satwa yang ada disekitar lingkungan yang dapat memberikan manfaat bagi manusia, diantaranya sebagai hewan peliharaan, estetika, bahan makanan, dan predator serangga pengganggu [1]. Disatu sisi burung juga memberikan dampak negatif yaitu hama pada tanaman pertanian [2], kotoran burung menimbulkan bau, namun masalah utamanya yaitu kotorannya sulit dibersihkan walaupun sudah disiram air [3]. Jenis burung yang sering hinggap dan berkeliaran di area gedung yaitu sriti, walet dan merpati. Namun pada yang paling mengganngu yaitu musim migrasi burung layang-layang Asia yang berkoloni sehingga menimbulkan kotoran yang banyak [4].

Perawatan gedung bagian luar terutama gedung bertingkat memerlukan biaya cukup tinggi sebanding dengan tingkat kesulitan dan kekotorannya. Penelitian pengembangan alat pembersih gedung untuk panel surya dengan wiper cukup efisien dalam membersihkan debu dan kotoran burung [5]. Namun alat tersebut tidak dapat dijadikan solusi untuk area gedung yang luas. Salah satu solusi yang diusulkan yaitu tindakan pencegahan dengan mengusir burung diarea gedung. Tren pemanfaatan atap gedung sebagai rooftop, seperti: taman, area santai, ruang produktif dan pembangkit listrik $[6,7,8]$ juga perlu antisipasi terkait dampak kotoran burung.

Penelitian terkait pengusiran burung telah banyak dilakukan untuk jenis hama sawah. Namun belum ada yang membahas pengusiran burung pada gedung. Pemanfaatan Sensor Passive InfraRed (PIR) untuk deteksi burung pipit [2, 9, 10, 11], deteksi hama burung menggunakan sensor ultrasonik [12, 13]. Sebagai besar 
output dari alat yang dikembangkan tersebut berupa suara yang dihasilkan dari aktifnya motor servo dan gelombang ultrasonik $[14,15]$.

Berdasarkan kajian lokasi dan akurasi maka penelitian ini menggunakan sensor RWCL karena deteksinya lebih baik dibandingkan dengan sensor ultrasonik dan PIR [16]. RCWL merupakan microwave motion sensor dengan prinsip kerja secara kontinyu mengirim gelombang mikro. Sensor mendeteksi gerakan dengan berubahnya sinyal, sesuai radar Doppler [17]. Sensor ini mempunyai sensitivitas tinggi, sudut dan jarak penginderaan yang besar. Sebagai outputnya menggunakan speaker ultrasonik dan suara predator yaitu burung elang untuk mencegah dan mengusir burung.

\section{Metode}

Perangkat yang digunakan dalam pengembangan alat ini yaitu sensor gerak RCWL-0516 sebagai deteksi gerakan, mikrokontroller arduino nano ATMega 328 yang portabel dan murah [18], speaker ultrasonic untuk memancarkan gelombang pengusir burung, speaker outdoor untuk bunyi burung elang, modul SIM 800 L untuk komunikasi data, relay, LED, LCD, dan power bank panel surya.

Tahapan pada penelitian ini diawali dengan analisis lingkungan gedung dan jenis burung, kemudian mengidentifikasi perangkat untuk mengusir burung, dilanjutkan dengan perakitan perangkat, pemprograman aplikasi, dan pengujian. Perakitan dimulai dengan PCB dengan menggunakan resistor untuk menjaga kestabilan pin dari gangguan gelombang elektromagnetik. Perakitan switch sebagai tombol kontrol alat, kemudian pemasangan SIM800L, LCD, relay, power supply, speaker ultrasonik, speaker, sensor RCWL pada 2 sisi pada arduino. Pemprograman menggunakan Arduino IDE 1.8.5 untuk konfigurasi alat, aplikasi monitoring berbasis web dibangun menggunakan PHP dan MySQL.

Sistem kerja dari alat ditujukkan pada Gambar 1, selanjutnya perangkat diuji pada skala laboratorium dan lokasi gedung. Tahapan pengujiannya yaitu pengujian deteksi pergerakan, pengujian speaker ultrasonik, pengujian speaker, pengujian modul SIM800L dan pengujian aplikasi web.

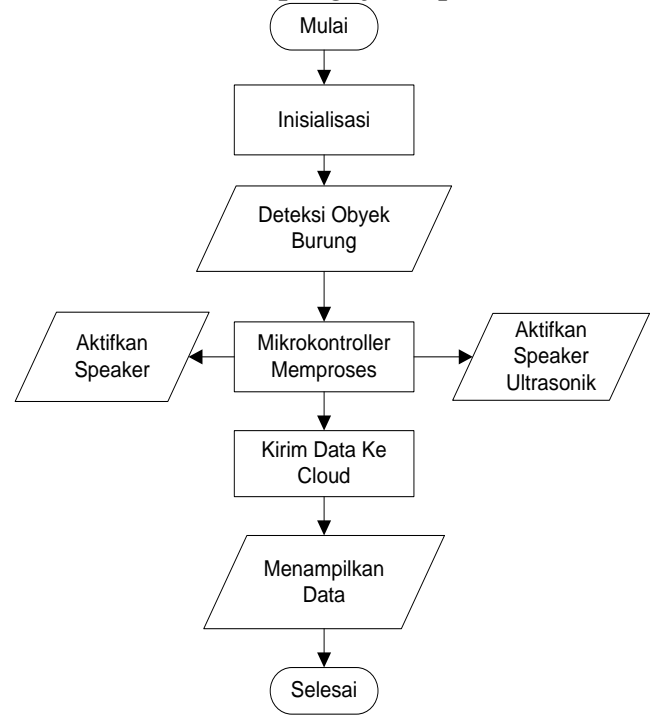

Gambar 1. Flowcart Sistem Kerja Alat

\section{Hasil dan Pembahasan}

Bagian Hasil perakitan PCB dengan memberikan tegangan positive 5v, menghubungkan pin dengan resistor $10 \mathrm{k} \Omega$ ke pin negative atau jalur ground. Pada perakitan switch, LCD dan LED ditempatkan pada panel, seperti pada Gambar 2.

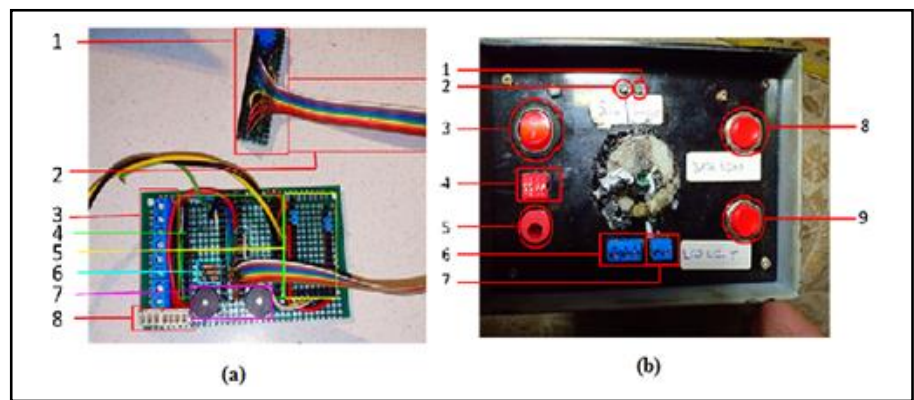

Gambar 2. Rangkaian (a) PCB (b) Switch 
Rangkaian SIM800L pada arduino dan rangkaian modul relay dan power supply, dapat dilihat pada Gambar 3a dan Gambar 3b Sensor RCWL dipasang di dua tempat agar bisa mendeteksi pergerakan burung dari arah yang berbeda, seperti Gambar 4a. Rangkaian keseluruhan dengan speaker dan ultrasonik, terlihat pada Gambar 4b.

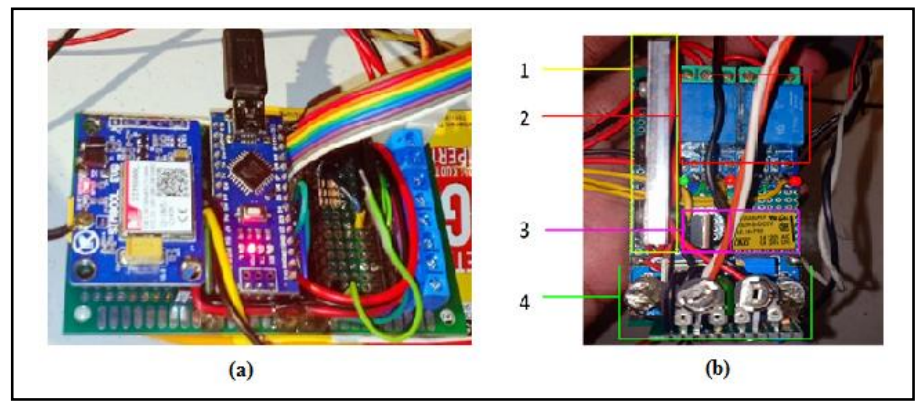

Gambar 3. Rangkaian (a) SIM800L (b) Switch Relay dan Power Suppy

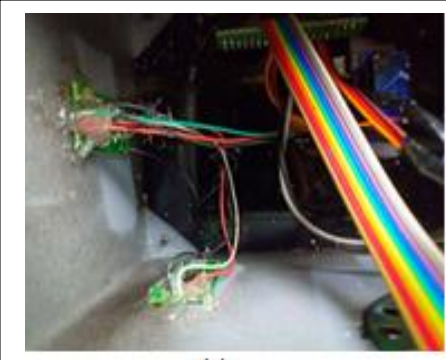

(a)

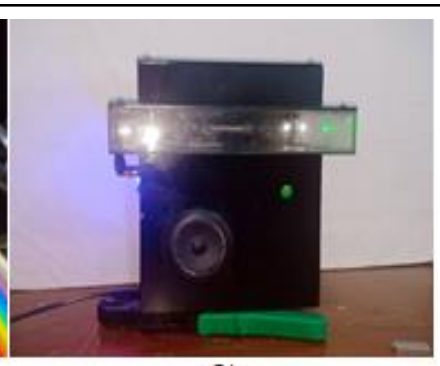

(b)

Gambar 4. Rangkaian (a) Sensor RCWL dan (b) Rangkaian Panel Keseluruhan

Pengujian perangkat dalam skala laboratorium untuk menguji kinerja perbagian perangkat. Yang pertama diuji yaitu akurasi deteksi sensor gerak RCWL dilakukan dengan menggerakan burung mainan pada jarak 1 hingga 3 meter dengan perubahan sudut $20^{\circ}$ hingga $45^{\circ}$ diperoleh obyek masih terdeteksi dengan baik yang artinya gerakan kecil masih terdeteksi, ditunjukkan grafik pada Gambar 5. Percobaan kedua dengan berjalan dari 7 meter ke arah mendekati perangkat sensor dengan posisi sejajar kemudian berhenti di jarak 5 meter dari sensor, kemudian posisi gerakan yang berbeda didapatkan hasil grafik mendekati hasil maksimum Yaxis, seperti pada Gambar 6. Dapat disimpulkan bahwa dalam percobaan ini gerak jalan manusia sudah dianggap pergerakan yang besar untuk sensor ini. Selanjutnya yaitu pengujian speaker bunyi burung elang jika terdeteksi gerakan bahwa adanya gerakan akan memicu suara speaker sekaligus gelombang dari speaker ultrasonik. Hasil pegujian bunyi menggunakan aplikasi $\mathrm{db}$ meter diperoleh hasil $63.4 \mathrm{db}-64.5 \mathrm{db}$, seperti pada Gambar 7.

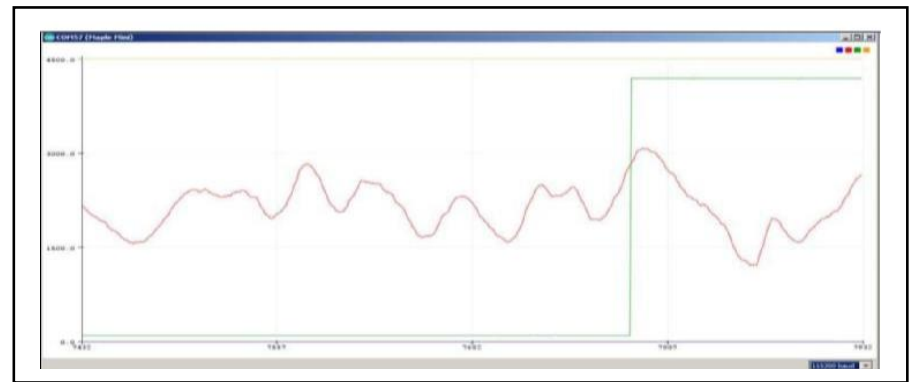

Gambar 5. Grafik Pengujian sensor RCWL

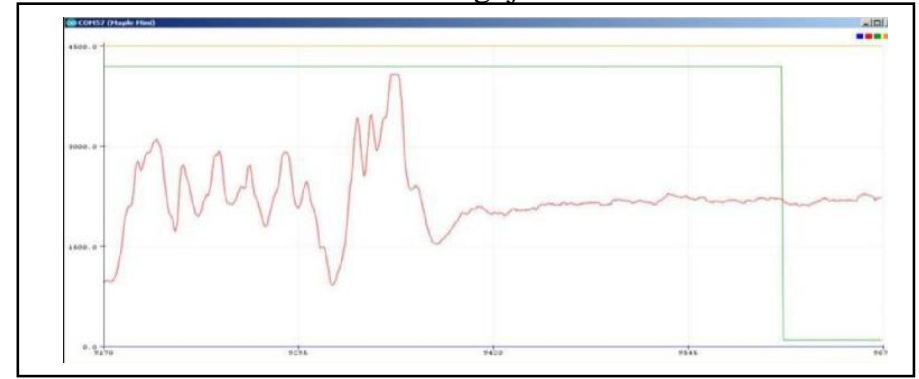

Gambar 6. Grafik Pembacaan Gerakan Jalan Mendekat kemudian Berhenti 


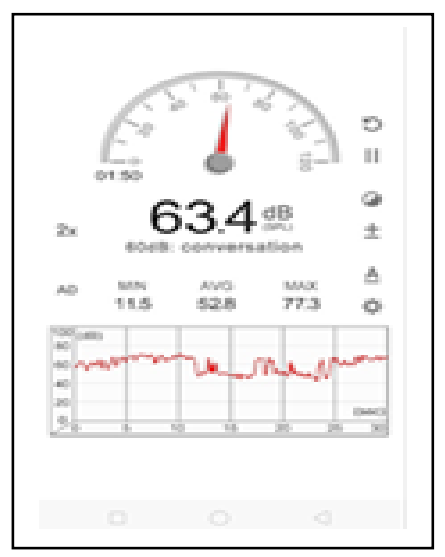

Gambar 7. Hasil Pengujian Bunyi dengan db Meter

Selanjutnya pengujian modul SIM800L dengan menggunakan Kartu SIM yang dipakai adalah tipe GSM dengan pengujian terhadap kualitas jaringan, respon waktu, cek respon IP Adress, inialisasi layanan HTTP, set identifikasi FTP, membaca data dari server dan cek terminal layanan HTTP telah berhasil, seperti pada Gambar 8.

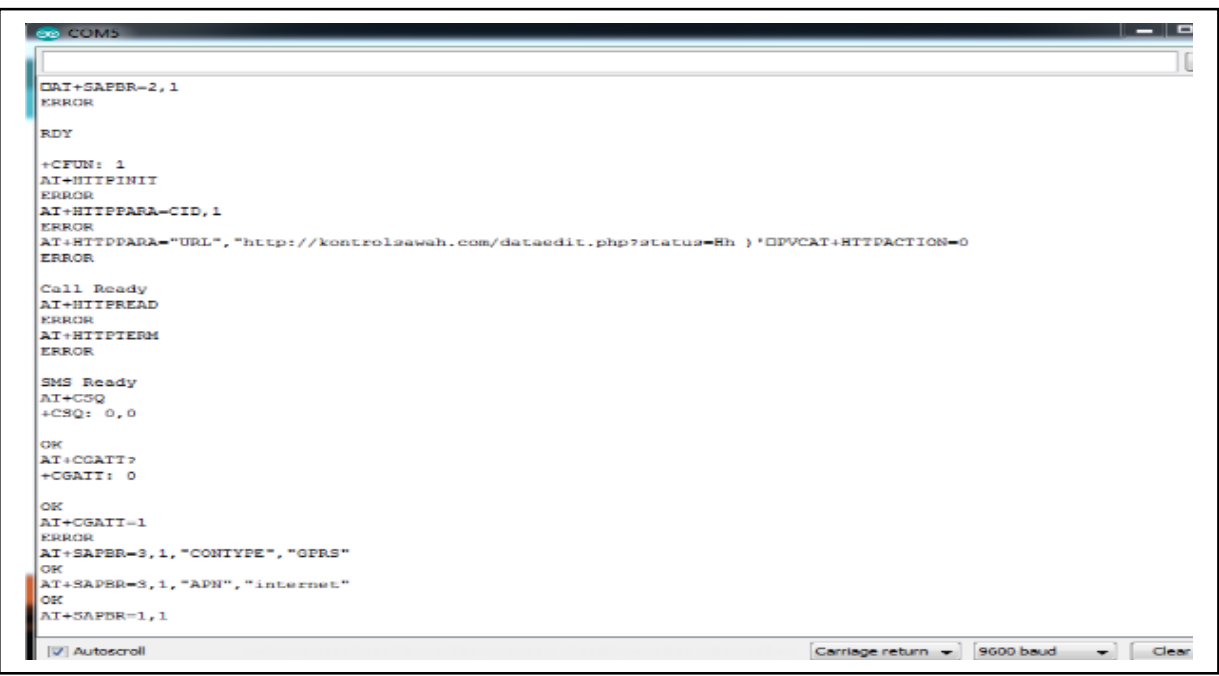

Gambar 8. Hasil Pengujian Modul SIM800L

Pengujian pengiriman data ke server telah berhasil dengan mendeteksi tiap gerakan yang dilaporkan pada menu dashboard pada Gambar 9.

\begin{tabular}{|c|c|c|c|c|}
\hline \multicolumn{4}{|c|}{$\leftarrow \rightarrow$ C (1) Tidak aman | kortrolsanahicom } & $\hat{\alpha}$ \\
\hline \multicolumn{5}{|c|}{ LAPORAN DATA MASUK DETEKSI BURUNG } \\
\hline \multicolumn{4}{|c|}{ Tampilikan $10 \vee$ data per halaman } & Pencarian: [ \\
\hline No & Tanggal & Waktu & & Notifikasi \\
\hline 1 & $2019-12 \cdot 12$ & 03:50:35 & Terdeteksi & \\
\hline 2 & 2019-11-17 & $00: 45: 42$ & Terdotelesi & \\
\hline 3 & 2019-11-17 & 02:02:56 & Terditeksi & \\
\hline 4 & $2019-11-18$ & 12:14:12 & Terdeteksi & \\
\hline 5 & 2019-11-19 & 11:58:20 & Terdeteksi & \\
\hline 6 & $2019-11-23$ & $02: 49: 47$ & Terdetelesi & \\
\hline 7 & $2019-11-25$ & 20:05:30 & Terdeterisi & \\
\hline 8 & $2019-11 \cdot 27$ & 01:52:10 & Terdetelksi & \\
\hline 9 & $2019-11-27$ & $02: 04: 37$ & Terdetelis & \\
\hline 10 & $2019-11-27$ & $62: 05: 25$ & Test connection & \\
\hline \multicolumn{4}{|c|}{ Menampilkan 1 s/d 10 dari 367 data } & $\langle\langle\langle 12345\rangle$ \\
\hline
\end{tabular}

Gambar 9. Pengujian Pengiriman Data ke Aplikasi Web

Pengujian selanjutnya pada lokasi gedung Fakultas Teknik Universitas Krisnadwipayana (FT UNKRIS). Perangkat dipasang pada salah satu sisi dinding gedung, dimana burung sering hinggap dan bersarang sehingga membuat dinding gedung menjadi kotor. Adapun jenis burung yang ada pada lokasi tersebut adalah burung sriti dan walet. Perangkat yang dipasang dengan penampakan pada Gambar 10. 


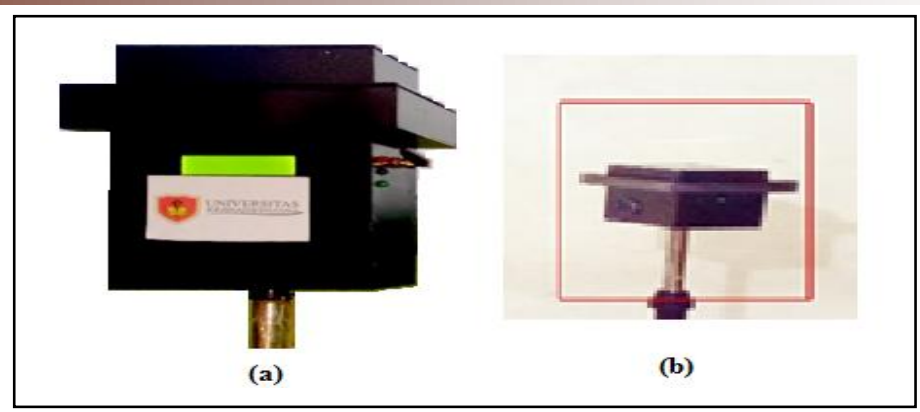

Gambar 10. Penampakan Perangkat (a) Belakang (b) depan dan jauh

Hasil pengujian perangkat, koneksi, pengiriman data dan aktifnya output speaker dalam deteksi pergerakan diringkas pada Tabel 1 .

Tabel 1. Pengujian perangkat, koneksi, pengiriman data dan aktifnya output speaker

\begin{tabular}{|c|c|c|}
\hline Pengujian & Kondisi & Hasil \\
\hline \multirow{7}{*}{ Sensor RCWL } & \multicolumn{2}{|l|}{ Uji Laboratorium: } \\
\hline & $\begin{array}{l}\text { Pergerakan kumpulan } 5 \text { ekor burung mainan arah mendekat dari jarak } 3 \\
\text { meter ke } 1 \text { meter dengan perubahan sudut } 20^{\circ} \text { hingga } 45^{\circ}\end{array}$ & Sensor mendeteksi \\
\hline & $\begin{array}{l}\text { Pergerakan kumpulan } 5 \text { ekor burung dari } 7 \text { meter ke arah mendekat sensor } \\
\text { dengan posisi sejajar kemudian berhenti di jarak } 5 \text { meter dari sensor }\end{array}$ & Sensor mendeteksi \\
\hline & \multicolumn{2}{|l|}{ Uji Lapangan: } \\
\hline & $\begin{array}{l}\text { Pergerakan kumpulan burung sriti atau wallet kearah mendekat sensor } \\
\text { jumlah lebih dari } 5 \text { ekor }\end{array}$ & Sensor mendeteksi \\
\hline & $\begin{array}{l}\text { - Pergerakan kumpulan burung kurang dari } 3 \text { ekor ke arah sensor pada jarak } 3 \\
\text { hingga } 5 \text { meter }\end{array}$ & $\begin{array}{l}\text { Sensor tidak } \\
\text { mendeteksi }\end{array}$ \\
\hline & $\begin{array}{l}\text { Pergerakan kumpulan burung kurang dari } 3 \text { ekor ke arah sensor pada jarak } 1 \\
\text { hingga } 2 \text { meter }\end{array}$ & Sensor mendeteksi \\
\hline Modul SIM800L & Sensor RCWL mendeteksi pergerakan burung & $\begin{array}{l}\text { Data berhasil dikirim } \\
\text { secara realtime }\end{array}$ \\
\hline Speaker & Sensor RCWL mendeteksi pergerakan burung & $\begin{array}{l}\text { Speaker aktif dengan } \\
60-75 \text { desibel }\end{array}$ \\
\hline Speaker ultrasonic & Sensor RCWL mendeteksi pergerakan burung & $\begin{array}{l}\text { Berhasil memancarkan } \\
\text { gelombang }\end{array}$ \\
\hline
\end{tabular}

Dari hasil pengamatan menggunakan kamera yang dipasang berdekatan dengan perangkat pengusir burung dibandingkan dengan data yang masuk ke server dan aktifnya speaker bahwa sensor RCWL dapat mendeteksi kumpulan burung sriti dan walet dengan baik. Namun saat burung walet hanya 1 ekor bergerak dengan cepat serta jarak sekitar 3 meter atau lebih dari perangkat, sensor RCWL terkadang tidak melaporkan adanya deteksi pergerakan. Hasil pengamatan dan evaluasi data deteksi bahwa sensor RCWL bekerja optimal dengan minimal kumpulan burung lebih dari atau sama dengan 3 ekor.

\section{Kesimpulan}

Pengembangan prototipe alat pengusir burung dengan sensor gerak RCWL mampu mencegah burung hinggap dan mengusir burung sriti dan walet pada gedung yang dapat dilihat dari hasil pengujian dan pengiriman data deteksi sensor ke server. Perangkat berhasil mengaktifkan bunyi burung elang sebagai predator dari speaker dan speaker ultrasonik saat sensor mendeteksi gerakan burung. Gelombang ultrasonik yang dipancarkan selain dapat mengusir burung juga mampu mengusir tikus. Namun sensor RCWL untuk kasus gerakan 1 ekor burung dengan cepat pada jarak lebih dari 3 meter terkadang tidak mampu mendeteksi dan sensor RCWL dapat mendeteksi optimal pada kumpulan burung lebih dari atau sama dengan 3 ekor. Untuk pengembangan dan akurasi deteksi lebih lanjut pada obyek yang kecil dan pergerakan cepat dapat menggunakan image processing.

\section{Ucapan Terima Kasih}

Kami ucapkan terima kasih FT UNKRIS dan Lab. IoT Prodi Informatika yang telah mendukung dalam sarana dan prasarana selama penelitian.

\section{Daftar Pustaka}

[1] F. A. Candra and R. Sumarmin, "Birds in The Air Tawar Campus of Padang State University, West Sumatra," Serambi Biol., vol. 5, no. 1, pp. 15-19, 2020.

[2] I. M. Noor, H. Fitriyah, and R. Maulana, "Sistem Pengusir Hama Burung pada Sawah dengan Menggunakan Sensor PIR dan Metode Naïve Bayes,” J. Pengemb. Teknol. Inf. dan Ilmu Komput., vol. 3, no. 9, pp. 9328-9333, 2019. 
[3] E. K. Dewangga, “Teror Kotoran Burung sampai Februari,” Radar Jogya, Yogyakarta, 22-Nov-2018.

[4] U. Hadi, "Burung Layang-layang Asia Migrasi ke Yogya, Pemkot Siapkan Ini,” Detik, 24-Nov-2018.

[5] M. R. W. Kusuma, E. Apriaskar, and D. Djunaidi, "Rancang Bangun Sistem Pembersih Otomatis Pada Solar Panel Menggunakan Wiper Berbasis Mikrokontroler," Techné J. Ilm. Elektrotek., vol. 19, no. 01, pp. 23-32, Apr. 2020, doi: 10.31358/techne.v19i01.220.

[6] E. Sejati, “Bisnis Model Canvas Harkostel Di Bandung Barat,” Sekolah Tinggi Pariwisata Bandung, 2020.

[7] R. P. Rizki, A. Marlina, and T. J. Daryanto, "Strategi Penerapan Optimalisasi Tata Letak Bangunan Pada Desain Pondok Pesantren Al-Muayyad Surakarta,” J. Ilm. Mhs. Arsit., vol. 3, no. 1, pp. 1-12, 2020.

[8] E. Tarigan and F. D. Kartikasari, "Analisis Potensi Atap Bangunan Kampus Sebagai Lokasi Penempatan Panel Surya Sebagai Sumber Listrik,” J. Muara Sains, Teknol. Kedokteran, dan Ilmu Kesehat., vol. 1, no. 1, pp. 101-110, 2020.

[9] M. A. Rahim, B. D. Sulo, and M. T. Alawiy, "Pengendali Hama Burung Dan Serangga Menggunakan Suara Dan Lampu Ultraungu Bertenaga Surya,” J. Sci. Electro, vol. 10, no. 1, 2019.

[10]H. T. Hidayat, A. Akhyar, and M. Mahdi, "Rancang Bangun Prototipe Pengusir Hama Tikus dan Burung Berbasis Internet of Things (IoT)," Pros. Semin. Nas. Politek. Negeri Lhokseumawe, vol. 3, no. 1, pp. 235-239, 2019.

[11] T. R. Agust, A. Aminudin, and A. Setiawan, "Sistem cerdas pengusik burung pipit sebagai hama padi menggunakan passive infrared dan pembangkit ultrasonik," in Prosiding Seminar Nasional Fisika 5.0, 2019, pp. 429-435.

[12] N. I. Adhitya, "Prototipe Alat Pengusir Hama Burung Pemakan Padi Disawah Berbasis Arduino Uno," J. Elektron. Pendidik. Tek. Elektron., vol. 7, no. 3, pp. 67-78, 2018.

[13] T. Silvia, "Rancang Bangun Alat Penghalau Hama Burung Berbasis Arduino Uno. Skripsi," Politeknik Ati Makassar, 2018.

[14]A. A. Mujab, M. Rosmiati, and M. I. Sari, "Rancang Bangun Alat Pengusir Hama Menggunakan Gelombang Ultrasonik,” eProceedings Appl. Sci., vol. 6, no. 1, pp. 340-348, 2020.

[15]L. R. Noer, G. A. Handiwibowo, and B. Syairudin, "Pemanfaatan Alat Pengusir Burung untuk Meningkatkan Produktifitas Pertanian di Kecamatan Sukolilo Surabaya,” J. Segawati, vol. 4, no. 1, 2020, doi: http://dx.doi.org/10.12962/j26139960.v4i1.6121.

[16] Q. Aini, U. Rahardja, H. Madiistriyatno, and F. Azharul, "Rancang Bangun Alat Monitoring Pergerakan Objek pada Ruangan Menggunakan Modul RCWL 0516," J. Tek. Elektro, vol. 10, no. 1, pp. 41-46, 2018.

[17]H. M. Ismail, C. G. Pretty, M. K. Signal, A. C. Amies, M. Haggers, and J. Geoffrey Chase, "Laser doppler vibrometer validation of an optical flow motion tracking algorithm," Biomed. Signal Process. Control, vol. 49, pp. 322-327, Mar. 2019, doi: 10.1016/j.bspc.2018.12.017.

[18] A. Muid, M. Zen, and R. Adriat, "Prototipe Alat Ukur Curah Hujan Berbasis Sensor Reed Switch dengan Antarmuka Website,” POSITRON, vol. 9, no. 1, p. 33, May 2019, doi: 10.26418/positron.v9i1.31696. 